\title{
Sale-Building Management Information System Based on C/S Model
}

\author{
Lihua Jiang ${ }^{1, a^{*}}$ and Aixia Zhu ${ }^{2, b}$ \\ ${ }^{1}$ School of Computer, Wuhan Polytechnic University, Wuhan Hubei, 430023,China \\ ${ }^{2}$ School of Animal Science, Wuhan Polytechnic University, Wuhan Hubei, 430023,China \\ ajianglihua@whpu.edu.cn, b415593244@qq.com
}

\section{Keywords: C/S; ADO; Database; Security}

\begin{abstract}
This paper introduces the designed method and main feature of Management Information System of sale-building based on C/S model, discusses the software architecture and the network model of the system. Through analyzing all kinds of business flow in the system, the paper has introduced the main function of all kinds of module and relation of all software module. we also detail MIS security question and the query and output of the system in the system conduct.
\end{abstract}

\section{Introduction}

As a new industry, the real estate grows a new force suddenly rises and has developed rapidly, and the housing sales is one of its main business. Sales management involves a large number of information and more types, The traditional information management system has many disadvantages, for example, repeated labor, low efficiency, can not provide timely all kinds of information in a timely manner, At the same time, with the further development of real estate, the volume of business continues to increase, The traditional means of enterprise information management is difficult to meet the requirements of modern management. On the other hand, with the rapid development of computer technology, Network technology has gradually penetrated into all aspects of social life, Companies have set up their own local area network, the information between different departments directly use the network to achieve sharing. The real estate industry is no exception, it is also an urgent need to use computer management. According to the actual situation of housing sales, which develop the corresponding application software, improve the level of company management decision, so then reducing business risk, easing labor, improving office efficiency. The author takes full account of the entire sales management process automation, and develops the sale-building MIS based on C/S model. This system is based on C/S model, which use the current series of mainstream technologies such as workflow technology, security technology, ADO technology, which use object-oriented methods. System configuration is flexible, safe and stable, which has achieved very good results in the practical application.

\section{System Goals}

As sale-building MIS, the system goals is to the local area network (LAN) as the basis, to the database as the core, which develop application software that meet the needs of Sale-Building management and development. Through full systematic research, which clarify the operation of the

To create a centralized database, the system consists of several functional modules, and data between modules needs to be fully shared.

To access to the information of various departments through the network.

To provide timely the sale red map, housing price, housing area, check in and so on, and provide decision support.

To provide a strong availability housing management which include entry, query, sales analysis and so on, which minimize manual input and manual calculation.

To generate automatically a variety of reports, and print reports in a number of ways.

To Provide a complete database maintenance function which include data backup, compression , recovery, action permission settings and so on. 


\section{System Design}

System Architecture Choice. The system is based on modern computer technology and communication technology, which is a comprehensive application system using Client / Server architecture. At the same time, which use workflow technology and security technology. Which meet the internal communication within the enterprise, and for the future development of the company's needs and expansion of the system to provide a strong support.

The C/S mode is a two-layer architecture that implements a collaborative approach by the client and the server. In the $\mathrm{C} / \mathrm{S}$ environment, the presentation layer and the functional layer including the display logic and the transaction logic component is placed on the client, but the data layer including data processing logic and the database is placed on the server side. Which collaborate to generate a task by connecting middleware. Client, server, and middleware that connects them constitute the $\mathrm{C} / \mathrm{S}$ basic structure, $\mathrm{C} / \mathrm{S}$ model has a set of application on the client, which its friendly interface enhances interactivity.

Workflow refers to the whole or part of the transaction process fully automated or semi-automated in the computer support. In the process, various texts, information and tasks are transferred from one person/place to another according to the established procedure rule. This system use widely workflow technology in applying to the manager for opening, closing, assigning roles, etc. The manager office application module adopts timing refresh, which master timely the information you need to approve, so that manager can make the right decisions in management.

Network Model. There are many techniques for building an office network, According to the system architecture The network structure of the system is LAN. For economic reasons, which will choose some high-quality and low-cost computer as server, then the user will use PC as client. The server installs the Windows Server operating system and the SQL Server database, and they together constitute the Intranet operating environment. The data consistency and security of each database subsystem are handled by SQL Server unified control. In the system of the C/S structure, the front handles input, output data and data interactions and so on, the background handles data query, retrieval, logical judgment and computing and so on, each workstation uses Windows 2010 to configure the TCP/IP protocol. The various functional modules of system communicate directly between the user and the database through ADO technology. The specific network model is shown in Fig. 1.

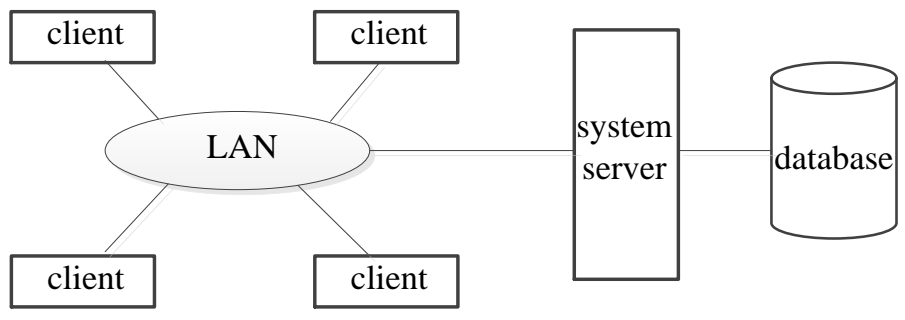

Figure 1. The network model of system

Business Process Analysis. In the sale-building management system, the housing information is entered by the planning department, customer to the front to fill in the customer registration card, salesman extract the house information to write the contact list, contract production department review the contact list and print it, then customer payment to cashier, and which settlement and check-in in the settlement department. Business flow diagram is shown in Fig 2.

System Functions. The system is divided into the following functional modules according to system goals, business process analysis and application needs:

Planning management module. Its main features include the rapid registration of real estate details during the system initialization phase. The system combining with the common of the house generates the real estate all the houses and the corresponding basic information, and the system supports a multi-room type of a building. Which manage all registered rooms and their details, including floor, room number, area, unit price, total price, orientation, type, structure, use and so on. which generate sales control table according to real-time sales automatically. 
Sales front management. Its main features include executing contact list, registering or modifying customer information with purchase intention or signed the contract. When an intended customer becomes a scheduled or official customer, in sales management registration directly pull-ins the prospective customer information, and no entering repeat. At the same time, to the formal customer it has the management and analysis of the system, avoiding data confusion, achieving advertising planning support and customer affinity management.

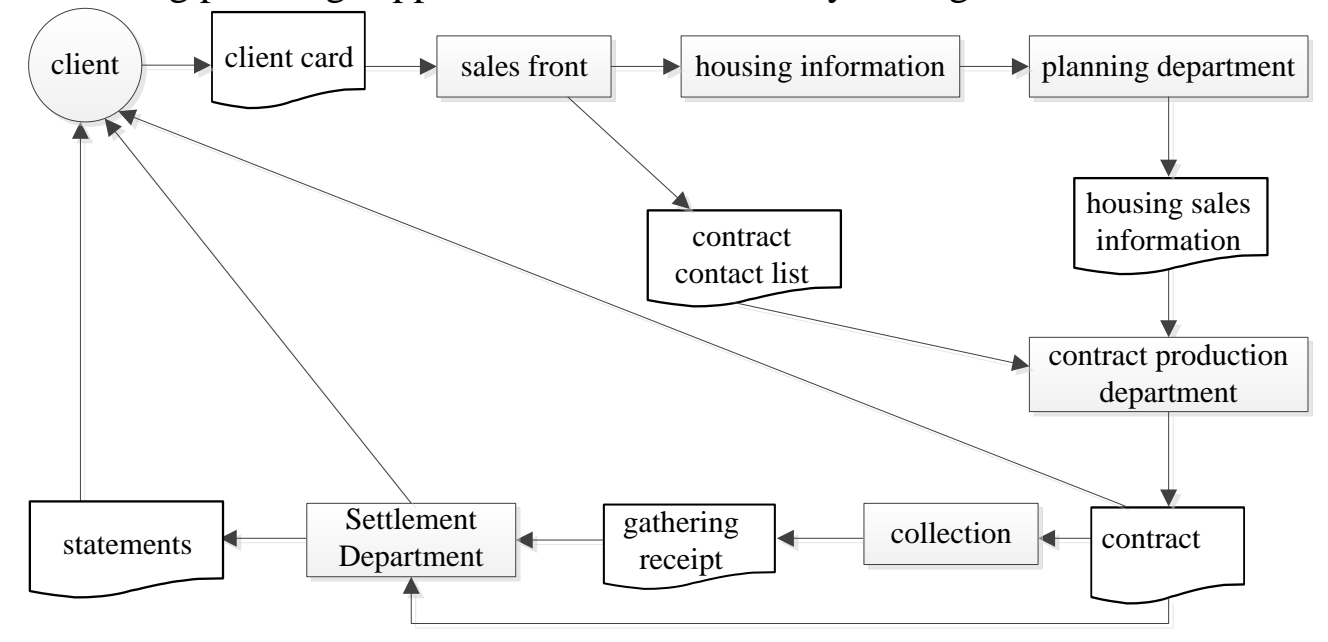

Figure 2. Sales management business flow diagram

Contract management. Its main features include defining the contract number, the system automatically generates the elements of the contract text according to the position, type, price, mode of payment of the salesman and customer talk. Which manage the contract, providing the necessary data for the financial and property, reflecting the status of real estate sales and sales progress.

Payment management. Its main features include entering general receipt. Which query the contract payment situation according to the housing location, contract number, receipt number, customer name, payment time, and which orientate accurately according to the payment type and payment amount. Which enter he visa fee and financial information, and which provide the interface with financial software. Firstly, which set up the subject around the receipt related, books etc. Secondly, which provide the interface for receiving the receipt. Finally, which complete the certificate import ability.

Settlement Management. Its main features include statements management, receivable notice management, refund certificate management, late fee deferred management etc. Which provide checking the default payment function, and printing the results of the query based on contract number, housing number, customer name, time period. When checking out or refund, checking out is available, so that ensure the uniqueness of home sales, at the same time the system automatically saves checking out original data, and can provide the checkout data for the finance. System handles customer change request, which displays sale state for seleted house, but which displays pending state for abandoned house, and changing the contract and other relevant data.

Network administrator module. Its main features include user management, role management, log management, customer information inquiry, company basic data maintenance, and various statistical reports.

System maintenance management. Its main features include data backup, data recovery, and Some auxiliary functions, for example, calling calculator, modifying display resolution, and software registration. The system overall block diagram is shown in Fig. 3.

\section{System Implementation}

In the sales management system, which don't only meet the current sales department business needs, but also consider the future development of the sale department. The whole system should be flexible, open, adaptable, and easy to operate, easy to maintain and secure. The following problems 
are solved in the system implementation.

Security. In MIS, Security is critical, It is critical to the functioning of the entire system. If the security of the system is not guaranteed, the system's data is corrupted or leaked, which the consequences will be severe. To the security of the system, It is guaranteed by the three protection measures.

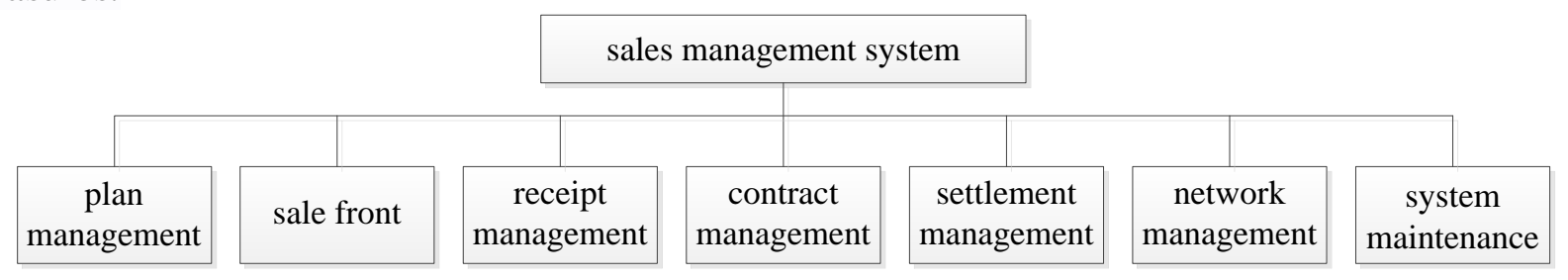

Figure 3. The system overall block diagram

Using firewall technology. Which create a layer of isolation between the external and the internal network to prevent the direct access to the server, and ensure the physical isolation of the server.

login verification. When the client first runs the system, the server is registered. Secondly, authentication is done by the user name password, and authenticated legitimate users can access the system based on their permissions. In this system, users are divided into super user, general operators and general users, which the user roles of NTFS and DBMS for Windows NT are licensed respectively at different levels. So the user can log in to SQL Server after the security validation of Windows NT. However, the corresponding data permissions need to be verified by SQL Server.

Data Backup and recovery. The front development tool Delphi implements backup and recovery of SQL Server databases. When a variety of unexpected events lead to data loss or damage, the system provide the data recovery functiond, data recovery, to ensure that the information system can be put into use as quickly as.

Query and output. This system provides a variety of ways for users to search for information such as housing, client and sales performance within the permitted limits. For example, query statement provides all queries related to the statements the selection criteria, can choose a kind of query conditions, also can choose a variety of query conditions, and can support fuzzy queries. For various query results, which can print multiple output formats and multiple styles, and which export to Execl editing.

\section{System characteristics}

The system has been put into trial operation in a real estate company. The system has the following characteristics.

1)The system has a friendly all-chinese man-machine interface. which provides user assistance instructions so that user operation.

2)The system provides a variety of query statistical display capabilities. The system uses ADO technology to convert data files into Execl data files, and further analyzes and processes them. The operation of the database is rich and quick.

3)The System is security. The system provides user security settings, password authentication and data backup and other security measures.

4)The whole system adopts modular structure, program design method, and independence is strong. The system can add other function modules according to the user's requirements, so it has certain extensibility.

\section{Conclusion}

This paper introduces the design and realization of a sales management system based on C/S, and which presents several key problems. In the trial run, the system is stable and reliable, which greatly improves the worker's efficiency, saves the office cost and obtains the good result. The practice 
shows that the design ideas of the system can be generalized to other property sales management, and we are promoting this system.

\section{Acknowledgements}

The paper is supported by 863Prgoram (Project No.2013AA102302) and the Natural Science Foundation of China (Project No.61502362).

\section{References}

[1]Workflow Management Coalition. Workflow Management Coalotion Terminology and glossary. Technical Report.WFMCTC-1011, Brussels:Reference Workflow Management Coalition, 2006

[2] Wassim I, Kayssi A, Application-layer End-to-end Security for M-commerce [J].Journal of Network and Computer Applications, 2009, 27(1):13-32.

[3] Ghosh A K, Swaminatha T M.Software Security and Privacy Rishsin Mobile E-commerce [J].Commuications of the ACM, 2007, 21:51-57.

[4] Chrysanthis P K. Transaction Procession in a Mobile Computing Environment, Proceedings of IEEE workshop on Advances in Parallel and Distributed Systems,2008,10:77-82.

[5] Byun S,Monn S.Resilient data management for replicated mobile database systems. Data and Knowledge Engineering,2006,29(1):43-55.

[6] Gao Jun, Feng Guangyin, Huang Caimei, Water-saving irrigation control system based on wireless sensor network[J]. Modern Electronics Technique, 2010(1):204-206.

[7] H.Li.Research on the humanities and social science achievement evulation mechanism in university[J]. Journal of Beijing Information Science \& Technology University, Beijing 2010,10(8):1-200

[8] Oh S,Park S Enterprise Model as a Basis of Administration on Role-based Access Control[J]. IEEE Computer,2009,5(10): 160-168.

[9] David F,Sandu R,Gavrila S. A Proposed Standard for Role-Based Access Control[J].ACM transactions On Information and System Security(TISSEC),2011,4(3):234-264.

[10] Samhu R,Coyne E,Feinstein H.Role-based access control models[J].IEEE Computer,2008,28(3):39-48.

[11] Ampatzidis Y G, Vouqioukas S G. Field experiments for evaluating the incorporation of RFID and barcode registration and digital weighing technologies in manual fruit barvesting[J]. Computers and Electronics in Agriculture,2009,66(2):166-172.

[12] Shi Junfeng, Ma Yongchang, Chen Jian. A web system for greenhouse monitoring based on wireless sensor networks[J]. Journal of Agricultural Mechanization Research,2009(2):76-79. 